\title{
Mercosul, política aduaneira e sistemas de cooperação: as políticas adotadas para o desenvolvimento da ciência no bloco de integração
}

\author{
Mercosul, customs policy and cooperation systems: the policies \\ adopted for the development of science \\ in the regional integration
}

\author{
Nicolas Addor ${ }^{1}$ \\ Luís Alexandre Carta Winter ${ }^{2}$ \\ Marco Antônio César Villatore ${ }^{3}$
}

\begin{abstract}
RESUMO:
O presente artigo faz uma análise sobre a política aduaneira atualmente em vigor no Mercado Comum do Sul - MERCOSUL e seus objetivos para com o fortalecimento do poder econômico do bloco. Dentro dessa análise, faz-se a abordagem sobre o desenvolvimento científico do MERCOSUL e sua relação para com a política aduaneira. Para isso, o artigo aborda inicialmente, de maneira breve, conceitos iniciais sobre integração regional e o processo de criação do bloco econômico para,após, desenvolver conceitos e críticas sobre os elementos que compõe o sistema aduaneiro do MERCOSUL, como a tarifa externa comum e o Código Aduaneiro comunitário, e sobre a cooperação internacional, que hoje possui grandes acordos com a União Europeia, principalmente na área científica. Utilizou-se, para tanto, do método dedutivo, amparada com pesquisas bibliográficas e documentais. Ao fim, conclui-se
\end{abstract}

\footnotetext{
${ }^{1}$ Mestrando bolsista (PROSUC/CAPES) em Direito na Pontifícia Universidade Católica do Paraná. Cursa especialização em Direito Constitucional na Academia Brasileira de Direito Constitucional. Bacharel em Direito pela Universidade Católica Dom Bosco. Membro do Núcleo de Pesquisas em Políticas Públicas e Desenvolvimento Humano (PUCPR) e colaborador do Grupo de Pesquisas Patrimônio, Direito e Diversidade (UCDB). Advogado. nicolasaddor@ gmail.com.Rua Brigadeiro Franco, 1897, ap.82, centro, CEP 80420-200

${ }^{2}$ Doutor em Integração da América Latina pelo USP/PROLAM e Mestre em Integração Latino-Americana pela Universidade Federal de Santa Maria. Advogado. Professor titular da Pontifícia Universidade Católica do Paraná na Graduação e na Pós-Graduação stricto sensu (Mestrado e Doutorado). Coordenador da Pós-Graduação (especialização) em Direito, logística e negócios internacionais na mesma instituição.E-mail: luisalexandrecartawinter@yahoo.com.br. Endereço: Rua Visconde do Rio Branco, nº. 1341- térreo. Cep: 80.420.210. Curitiba/Paraná.

3 Pós-Doutorado em Direito pela UNIROMA II "TOR VERGATA", Mestre em Direito pela Pontifícia Universidade Católica de São Paulo e Doutor em Direito pela Universidade de Roma I, "La Sapienza", revalidado na Universidade Federal de Santa Catarina, Professor de Direito do Trabalho na Pontifícia Universidade Católica do Paraná (PUCPR), na Graduação e na Pós-graduação (Mestrado e Doutorado), Coordenador do curso de Especialização em Direito do Trabalho na PUCPR, Conselheiro Geral do Instituto dos Advogados do Paraná (IAP), Presidente da Associação dos Advogados Trabalhistas do Paraná (AATPR). Advogado em Curitiba-PR, e-mail: prof.villatore@gmail.com. Endereço: Rua Visconde do Rio Branco, no. 1341- térreo. Cep: 80.420.210. Curitiba/Paraná.
} 
que a política aduaneira vai muito além do viés econômico e mercadológico que ela possui, influindo também na cooperação, exportação e importação de materiais, pesquisadores e acadêmicos tão necessários para o avanço na área científica.

Palavras-chave: Política Aduaneira; Mercosul; Direito comunitário; Integração; desenvolvimento científico.

\begin{abstract}
:
This paper analyzes the customs policy currently in force in the Southern Common Market MERCOSUL and its objectives for strengthening the bloc 's economic power. Within this analysis, the approach is made to the scientific development of MERCOSUL and its relation to the customs policy. The paper initially briefly discusses initial concepts about regional integration and the process of creating the economic bloc, after which to develop concepts and critiques about the elements that make up the MERCOSUL customs system, such as the common external tariff and the Community Customs Code, and on international cooperation, which now has major agreements with the European Union, mainly in the scientific field. For this purpose, the deductive method was used, supported by bibliographical and documentary research. Finally, it is concluded that the customs policy goes far beyond the economic and market bias that it has, also influencing the cooperation, export and import of materials, researchers and academics so necessary for the advancement in the scientific area.
\end{abstract}

Key-words: Customs Policy; Mercosul. Community Law; Integration; cientific development.

\title{
1. Introdução
}

No geral, a noção que se concebe sobre política aduaneira, seja de um Estado ou um bloco regional, fixa-se no sentido de defesa à soberania, especialmente com a defesa da atividade econômica. O conceito, no entanto, não é de todo equívoco: a política aduaneira é destinada à proteção do mercado, mas, além disso, ela é também atribuída para cumprir objetivos sensíveis como a cooperação econômica, social e científica de um Estado.

Desde muito tempo, antes até mesmo da concepção moderna de Estado, a defesa da soberania se manteve como uma real necessidade ante aos Estados alheios. A identidade de um povo ou a defesa do território são justificativas concretas para que, ao longo da história, o controle da administração pública sobre a faixa de fronteira fosse de grande relevância. Exemplos notórios ao longo da história humana não faltam: desde pretensões xenofóbicas, em desfavor de um povo ou indivíduos pertencentes à uma determinada religião, para que não entrem em seu território; para proteger a indústria nacional, coibindo a instalação de sociedades empresariais estrangeiras, ou, ao contrário, facilitar o ingresso de empresas estrangeiras para aumentar o nível de empregabilidade do país; do mesmo modo, controlar a 
movimentação de pessoas e bens para proteger a fauna e flora local, impedindo a entrada de animais e plantas não pertencentes à região.

Num contexto mais regional pode-se observar a política aduaneira em diversos atos, como se verifica na não abertura dos portos brasileiros até 1808, com o Decreto de Abertura dos Portos às Nações Amigas, em razão da garantia de dependência da colônia com Portugal ou de adoção de políticas mais liberais para a atração de empresas estrangeiras ocorridas no Chile no final do século XX.

Nesse sentido, o MERCOSUL surgiu em um cenário geopolítico global, onde se viu necessário, em termos econômicos, a criação de práticas regionais destinadas a defender a soberania econômica e manter o desenvolvimento dos países latinos americanos, é um dos sub-blocos da ALADI (Associação Latino Americana de Desenvolvimento), criada em 1980 e sucessora da ALALC (Associação Latino Americana de Livre Comércio), criada em 1960.

O objetivo do presente artigo é correlacionar as políticas aduaneiras pautadas no desenvolvimento e fomento da ciência, dentro do bloco. Para tanto, pretende responder as questões: Há, dentro do bloco, como política aduaneira, medidas que visem, conscientemente, incrementar o fomento da ciência? E se há, em que consistem?

Para responder as questões, utilizando-se do método dedutivo, amparado com pesquisas bibliográficas e documentais, dividiu-se o estudo, trabalhando-se, inicialmente, com uma contextualização, a seguir, com o processo de harmonização da política aduaneira do MERCOSUL, tarifa externa comum, código aduaneiro do MERCOSUL, informatização dos trâmites aduaneiros, sistema de pagamentos em moeda local, o Fundo de Convergência Estrutural do MERCOSUL (FOCEM), a cooperação científica Internacional, a cooperação científica no MERCOSUL, para então chegar a conclusão pretendida.

\section{O processo de harmonização da política aduaneira do MERCOSUL}

A ALADI, acordo de alcance regional, constituído pelo Tratado de Montevidéu de 1980, englobando quase a totalidade dos países da América do Sul e alguns outros Estados da América Central, do Norte e Caribe. ${ }^{4}$ Os países da ALADI buscam a integração e formação de um mercado comum latino-americano, por meio de acordos de alcance regional, acordos de

$4 \quad$ Mais especificamente, a ALADI possui treze Estados-membros: Argentina, Bolívia, Brasil, Chile, Colômbia, Cuba, Equador, México, Panamá, Paraguai, Peru, Uruguai e Venezuela. Em: Associação Latino Americana de Integração. Disponível em: <http://www.aladi.org/sitioAladi/quienesSomos.html>. Acesso em: 03 fev. 2018. 
alcance parcial e uma área de preferência tributária que englobam todos os Estadosmembros. ${ }^{5}$

Como acordo de alcance regional, o MERCOSUL foi registrado na ALADI como AAP.CE n. ${ }^{\circ} 18$, classificada como "agrupación subregional de integración" ao lado da Comunidad Andina de Naciones -CAN, essa última formada, originariamente, pela Colômbia, Equador, Peru e Bolívia,( este último encontra-se em processo de inclusão no MERCOSUL) .

É objetivo dos Estados latino-americanos alcançarem um grau de qualidade de vida e estabilidade econômica e social, recorrendo, para tanto,ao apoio mútuo e criação de uma identidade regional.

Embora inicialmente o MERCOSUL fora destinado estritamente para promover políticas macroeconômicas de seus Estados-membros, em razão da demanda social, da qual nascem os direitos, passa a trabalhar (não sem resistências) com uma pauta, dentro da integração regional, dando a devida atenção ao desenvolvimento humano. ${ }^{6}$

Torna-se aqui necessária, uma breve explanação sobre o início e transformação da política aduaneira do MERCOSUL, bem como a contextualização de conceitos que trabalhados, para, logo após, analisar as diversas políticas aduaneiras que o bloco econômico atualmente pratica, para que, e só então trabalhar com a importância da cooperação científica, como meio necessário para o desenvolvimento e o processo integralizador, entrelaçamento política aduaneira, com e como mecanismo de cooperação e desenvolvimento científico.

A construção de um direito com aplicabilidade internacional e a expansão da interdependência possibilitam a integração entre os Estados em diferentes aspectos. O processo pode seguir duas vertentes: a regional ou a global. No plano regional os Estados unem-se a outros Estados próximos onde os avanços na integração são facilitados por diferentes fatores. No plano global, os Estados se unem com dezenas, ou até mesmo centenas de diferentes outros Estados para a formulação de processos comum de integração. Nessa concepção, os Sistemas regionais de integração são processos jurídico-políticos de aproximação entre Estados de uma mesma região geográfica para a criação de sinergias. ${ }^{7}$

\footnotetext{
5 Associação Latino Americana de Integração. Disponível em: <http://www.aladi.org/sitioAladi/quienesSomos.html>. Acesso em: 03 fev. 2018.

6 WINTER, Luís Alexandre Carta. Desenvolvimento e integração regional: a atuação do MERCOSUL em políticas públicas de direitos humanos. Revista de direitos humanos em perspectiva, Curitiba, v.2, n.2, p.112-127, jul./dez. 2016, p.125.

VARELLA, Marcelo D. Direito Internacional Público. São Paulo: Saraiva, 2016, p.381.
} 
Mercados de distintas nacionalidades, quando integrados, manifestam-se por um fluxo contínuo e significativo entre os países envolvidos, com o efeito imediato, da integração, de ampliação de tais mercados, seja pelo lado da oferta, seja pelo lado da demanda, com a incorporação de novas áreas geográficas e na expansão no número de consumidores e fornecedores. A tendência de integração sempre é, num primeiro momento, espontânea, fruto do próprio caráter competitivo das empresas nacionais quando em processo de expansão para o estrangeiro. No entanto, se por um lado a concorrência possibilitou a integração econômica natural, ela, por outro lado, engendrou problemas macroeconômicos, como desemprego e desequilíbrios externos, decorrentes da desigualdade econômica entre os Estados.

Devido aos graves problemas econômicos gerados, houve como reação práticas protecionistas, que geraram externalidades negativas para o comércio e o crescimento econômico internacional. Com essa grande problemática vagando sobre os mercados de cada Estado, a indução da integração por políticas econômicas surgiu nesse contexto, estabelecendo união de diferentes Estados a fim de promover um fortalecimento mútuo de seus mercados e garantir o desenvolvimento. ${ }^{8}$

$\mathrm{Na}$ integração regional, existem cinco gradações reconhecidas pelo direito internacional: Zona de preferência tarifária; Zona de livre comércio; União aduaneira; Mercado comum; União econômico-monetária.

As duas primeiras, com importância menor neste estudo, merecem, contudo, destaque para a compreensão geral do processo de integração. Na considerada "primeira fase de integração", a zona de preferência tributária, como o próprio já denuncia, seria a tributação inferior de produtos de importação oriundos do Estados-partes assinantes do tratado. Esse tratamento é logo alterado na segunda fase, a zona de livre comércio, em que os tributos de importação em grande parte dos produtos são zerados, além de se reduzir as barreiras alfandegárias. $^{9}$

$\mathrm{Na}$ terceira fase de integração, Marcelo Dias Varela ressalta que na união aduaneira, além de não haver tributos para uma parcela importante do comércio intrazona sobre os produtos fabricados na região, existe uma tarifa externa comum, em outras palavras, um tributo padrão que os Estados cobram sobre a importação de produtos oriundos de outros Estados. Deste modo, o que se explicita é a articulação entre os Estados para homogeneizar seu comércio dentro e fora do bloco, com o objetivo coordenar políticas para proporcionar

8 STUDART, Rogério; HERMANN, Jennifer. Estrutura e operação dos sistemas financeiros do MERCOSUL: perspectivas a partir das reformas institucionais dos anos 1990. Brasília: IPEA, 2001, p.103-104. $9 \quad$ VARELLA, Marcelo D. Op. Cit, p.382. 
uma integração mais rápida e inteligente, por meio da articulação de suas políticas externas. Evita-se assim, nesse processo, que produtos produzidos fora do bloco dificultem o processo de integração. ${ }^{10}$

O Mercado Comum corresponde a um estágio superior em que há a circulação sem restrições de bens, serviços e fatores produtivos, bem como a política externa comum e a coordenação de políticas macroeconômicas e harmonização tributária. ${ }^{11}$ Por fim, a união econômico-monetária, a política econômica e monetária se encontra totalmente integrada entre os Estados, principalmente com a existência de uma moeda comum, além da livre circulação de bens, serviços e produtos. ${ }^{12}$

Voltando-se nas uniões aduaneiras, estágio atual do MERCOSUL, elas têm como premissa básica o fato de que as mercadorias de procedência estrangeira, uma vez ingressas no território aduaneiro comum, passam a ter livre circulação e não devem mais ser tributadas. A referida decisão do Conselho Mercado Comum, nesse sentido, estabeleceu que os bens importados por um membro do MERCOSUL, que tenham cumprido a política tarifária do bloco, receberão o tratamento de bens originários, tanto para fins de circulação econômica quanto na hipótese de incorporação em processos produtivos.

É possível afirmar que a concepção de um mercado comum na América do Sul foi principiada pelo Programa de Integração e Cooperação Econômica entre a Argentina e o Brasil (PICE) ${ }^{13}$, de 1986, que visava, à época, integrar num processo contínuo e gradual, as duas maiores economias da região. Logo após, em 1988, esse processo foi acelerado com a assinatura do Tratado de Integração, Cooperação e Desenvolvimento, que estabelecia um prazo máximo de dez anos para se atingir uma zona de livre-comércio, a harmonização gradual das políticas setoriais e a coordenação das políticas macroeconômicas. ${ }^{14}$ Sem embargo, como já é sabido, o desenvolvimento do bloco regional latino-americano vem caminhado a passos lentos, visto que pouco se alterou da década de 1990 para a década de 2010.

$10 \quad$ Idem.

11 KUME, Honorio; PIANI, Guida. Mercosul: o dilema entre união aduaneira e área de livre-comércio. Revista Economia Política, São Paulo, v.25, n.4, p.370-390, 2005, p.371.

12 VARELLA, Marcelo D. Op. Cit., p.383.

13 De acordo com Elizabeth Accioly, o "embrião da integração sul-americana deve-se à aproximação entre o Brasil e a Argentina, em meados da década de 80 do século XX. A semente germinou e hoje alastra-se por todo o continente. É de se destacar, por derradeiro, um dos grandes benefícios da proliferação dessa semente integradora, algo muito caro para qualquer Estado, termómetro da seriedade, do respeito aos direitos humanos e do seu fortalecimento na cena internacional: a democracia”. Em: ACCIOLY, Elizabeth. Duas décadas de MERCOSUL: valeu a pena? Revista Lusíada, Lisboa, n.5, p.125-140, 2011, p.140.

$14 \quad$ KUME, Honorio; PIANI, Guida. Op. Cit., p.370. 
No entanto, Elizabeth Accioly faz uma importante pontuação quanto ao processo temporal de integração regional do MERCOSUL, ao ressalvar que a trajetória para um mercado comum cristalino não se percorre em poucos anos, como previsto erroneamente no Tratado de Assunção. A autora exemplifica com o processo de integração da União Europeia, que demorou mais de trinta e cinco anos para alcançar a abertura de fronteiras e que, mesmo assim, ainda carece de pequenos ajustes no Espaço Schengen. ${ }^{15} / 16$

De fato, a integração entre os Estados deve ocorrer com a cessão recíproca de políticas protecionistas, ao mesmo tempo que as diferenças culturais, sociais e econômicas devem ser deixadas de lado. Outrossim, a reciprocidade deve incidir sobre capitais, bens e serviços, utilizando de quatro instrumentos básicos para fazer avançar a associação: um programa de liberação comercial, a convergência de políticas macroeconômicas, a criação de uma tarifa externa comum e a adoção de acordos setoriais. ${ }^{17}$ Seis ferramentas atualmente em vigor no bloco serão explicitadas a seguir, de acordo com o método utilizado pelo MERCOSUL.

A tarifa externa comum - TEC, consiste numa alíquota padrão de cobrança sobre produtos importados originários de Estados não pertencentes a um bloco econômico e com aplicação uniforme, ressalvados os produtos das listas de exceções. Segundo Varella, a tarifa tem como objetivos: o aumento da competitividade intrabloco, em face dos produtos externos, a preservação das conquistas já realizadas (desenvolvimento socioeconômico) e possibilidade de garantir maior unidade nas negociações comerciais com outros Estados e blocos regionais..$^{18}$

No MERCOSUL, as listas de exceções à TEC foram fixadas inicialmente com um número restrito de produtos. Na prática, entretanto, existem diversas exceções, que são prorrogadas sucessivamente, dificultando o avanço do processo de integração.Além das exceções, existem medidas de tratamento diferenciados, adotadas tradicionalmente para tentar compensar os sócios com menor poderio econômico, têm como base mecanismos indiretos, como o maior número de exceções à Tarifa Externa Comum. Gustavo Rosolen Tessari critica a existência de exceções à TEC, por considerar que, além de insuficiente, ela ainda provocou o surgimento de dificuldades para o aprofundamento e o fortalecimento institucional, justificando que o estabelecimento de uma tarifa comum para o comércio com terceiros é

15 ACCIOLY, Elizabeth. Duas décadas de MERCOSUL: valeu a pena? Revista Lusíada, Lisboa, n.5, p.125-140, 2011, p.131.

16 O Espaço Schengen é uma zona dentro da Europa que abarca Estados da União Europeia e Estados fora do bloco regional em que há livre circulação de pessoas, serviços e bens, com fronteiras abertas.

17 VARELLA, Marcelo D. Op. Cit., p.388.

18 Idem, p.388-389. 
condição essencial para que o bloco se consolide enquanto uma união aduaneira, e para que possa alcançar o seu objetivo de chegar ao estágio de mercado comum como anunciado no Tratado de Assunção. ${ }^{19}$

Ademais, grande parte das justificativas para a manutenção de diferenciação das tarifas provém de argumentos macroeconômicos, os quais os países membros acabam por referendar as demandas. No entanto, os custos dessa proteção adicional são assumidos, geralmente, pelo país interessado, o que permite evitar conflitos regionais em razão dessas medidas de flexibilização da tarifa externa comum. ${ }^{20}$

Honorio Kume e Guida Piani trouxeram duras críticas quanto a estrutura tarifária, indagando sobre o número excessivo de alíquotas, em detrimento de uma simplicidade maior e necessária na administração aduaneira e também à falta de uniformidade da proteção, privilegiando a escalada na tarifa nominal com o objetivo de garantir uma proteção efetiva crescente em cada etapa da estrutura produtiva. Os autores, entretanto, fazem uma ressalva na crítica quando destaca os benefícios que ela proporcionou, pois, o número excessivo de alíquota possibilitou acomodar os interesses dos países membros, ao mesmo tempo que a escalada da tarifa nominal reproduziu o dogma predominante de que as proteções efetivas de bens finais devem ser superiores à de bens intermediários e de capital. ${ }^{21}$

Sem embargo, se não bastassem as críticas quanto às "perfurações" da tarifa externa comum, chama atenção o tempo utilizado para se criar uma verdadeira integração econômica sub-regional, que demorou quase 20 anos. Em 2010, foi estabelecido um tratado para colocar em prática os objetivos do MERCOSUL com a justiça social distributiva. Toda renda aduaneira angariada por meio da TEC seria redistribuída com fundamento no desenvolvimento da região como um todo e também como um mecanismo de compensação (principalmente para o Paraguai) decorrente das perdas de lucros provenientes da cessão de cobrança de impostos de importação de forma direta, devido à extinção da dupla cobrança da TEC. ${ }^{22}$

19 TESSARI, Gustavo Rosolen. Integração regional, fundos estruturais e estabilidade institucional no MERCOSUL: a criação do FOCEM. Perspectivas, São Paulo, v.42, p.115-137, jul./dez. 2012, p.122.

20 KUME, Honorio; PIANI, Guida. Op. Cit., p.371.

$21 \quad$ Idem, p.376.

22 BOTELHO, Martinho Martins. Novo Mecanismo de Distribuição de Renda Tributária-Aduaneira no MERCOSUl. Revista Eletrônica do Curso de Direito das Faculdades OPET. Curitiba, n. 9, p. 171-182, jan./jun. 2013, p.171. 
Isso pois fim a uma ampla discussão quanto à Tarifa Externa Comum, que, desde 2004 com as decisões do Conselho do Mercado Comum n. 54/2004 e 37/2005 iniciaram a gradual eliminação da dupla cobrança da TEC e da distribuição da renda Aduaneira.

Foi firmado, ainda, o compromisso de aprovação, previsto inicialmente para até 2008 para a sua formulação e promulgação pelos Estados-parte, do Código Aduaneiro do MERCOSUL, com o objetivo de facilitar e controlara circulação de mercadorias, tanto àquelas provenientes do exterior como do mercado intrabloco. Entretanto, o prazo não foi observado, num contexto em que apenas em agosto de 2010, após seis anos de intensas negociações, o código foi finalmente aprovado, por meio da decisão do Conselho do Mercado Comum n.27/2010. ${ }^{23}$

Para Luís Eduardo Schoueri, a política tributária do MERCOSUL apresenta um processo contínuo de harmonização, que passa por três graus. Nessa lógica, o primeiro grau refere-se ao que o autor nomeia como "Coordenação", no que consiste numa formação de estratégias e decisões dos Estados membros com um objetivo comum. No segundo grau, a "Harmonização" stricto sensu, além das políticas comuns, há o reconhecimento de princípios legislativos comuns, trazendo em si a comparabilidade dos sistemas. Na terceira fase, apelidada como "Uniformização", além de uma única identidade dos princípios legais, a regra positivada é uniforme. ${ }^{24}$

Portanto, é na lógica da uniformização e na tentativa de garantir uma identidade regional que o Código Aduaneiro do Mercosul surgiu num contexto de embates econômicos ainda não solucionados. ${ }^{25}$

$\mathrm{Na}$ tentativa de promover a padronização, celeridade e maior fluidez na troca de informações entre as aduanas dos países membros, foi implantado também o sistema INDIRA, que permite a conexão online entre todos os sistemas aduaneiros, bem como o seu processo de informatização. Entre os benefícios, destaca-se a maior precisão de digitalização de certificados de origem e outros documentos exigidos para a circulação de mercadorias,

23 CAPARRO, Roberto. Comércio Internacional Esquematizado. São Paulo, Saraiva, 2012, p. 323.

24 SCHOUERI, Luís Eduardo. Harmonização Tributária no MERCOSUL. Revista Direito Mackenzie, São Paulo, n.2, p.169-178, 2015, p.172-173.

25 Nesse sentido, Elizabeth Acciolyfez a seguinte observação no então recém aprovado Código Aduaneiro: "A recente aprovação do Código Aduaneiro do MERCOSUL, em 3 de agosto de 2010, que esperou mais de uma década por esse momento, foi, sem dúvida, uma grande vitória, mas o MERCOSUL ainda enfrenta muitas barreiras não tarifárias e alguns conflitos económicos pontuais. Desde já é importante ressaltar que os conflitos sempre são salutares quando há integração - isso significa que há vida no bloco-, e o seu reflexo encontra-se estampado, com alguma regularidade, nas primeiras páginas dos jornais, e atende pelo título de "guerras comerciais", na maioria das vezes com dois protagonistas recorrentes - o Brasil e a Argentina. Dentre estas, a guerra dos calçados, a guerra da linha branca de electrodomésticos, a guerra dos pneus, a guerra das bicicletas entre tantas outras. Em: ACCIOLY, Elizabeth. Op. cit., p.131. 
bem como a simplificação do procedimento de despacho aduaneiro intra MERCOSUL. ${ }^{26}$ Tratada na Decisão número 37 de 2005 do Conselho do Mercado Comum, o sistema deveria ser implementado até 2008.

Interessante que na XXVIII Reunião Ordinária do Conselho do Mercado Comum, os Estados-membros mencionaram de forma uníssona a necessidade de um sistema informatizado para a construção de uma base de dados para que haja informações suficientes para a distribuição da renda aduaneira do MERCOSUL $\cdot{ }^{27} \mathrm{~A}$ informatização da aduana, criando um sistema de big data, junto com o Código Aduaneiro Regional, possibilita que se crie uma alfândega do MERCOSUL, em detrimento das aduanas existentes dos Estados soberanos.

Desde 2008 iniciou-se com um acordo entre Brasil e Argentina o Sistema de Pagamentos em Moeda Local (SML), após conversas entre os Bancos centrais dos dois Estados. O SML é destinado a operações comerciais entre importadores e exportadores comerciais, e possibilita que o pagamento e recebimento possa ser realizado nas suas respectivas moedas. ${ }^{28}$

O Sistema possibilita o fortalecimento do mercado real/peso, antes balizadas pelo dólar. Com isso, reduz-se os custos operacionais e diminui as etapas do processo de conversão. A paridade entre as moedas é feita pela taxa SML, com o valor sendo calculado diariamente com base na razão entre a taxa média de fechamento da cotação do real em relação ao dólar e a taxa de cotação do peso argentino com a moeda estadunidense. ${ }^{29}$

Mesmo que nem todos os Estados-membros estejam envolvidos no projeto do Sistema de Pagamentos em Moeda Local, a facilitação no processo de câmbio nas exportações e importações dos dois Estados mais economicamente fortes do bloco acarreta o fomento do comércio intra-bloco, servindo ainda como um método paliativo enquanto a região não instituir uma moeda única.

No âmbito do Mercado Comum do Sul foram também criados programas específicos, destinados principalmente à integração produtiva de seus membros, bem como a coesão social, o desenvolvimento de competitividade, convergência estrutural, e o incentivo às micro

26 CAPARRO, Roberto. Op. cit., p.323.

27 Nesta reunião, inclusive, como enfatizado por Matinho Martins Botelho, havia a necessidade de, além da implementação do sistema INDIRA, a criação do Código Aduaneiro do MERCOSUL e de "um mecanismo para avaliação de circunstâncias especiais e específicas dos Estados-partes relacionadas aos eventuais impactos resultantes da aplicação da livre circulação de mercadorias na sub-região". Deste modo, somente com o cumprimento de tais requisitos haveria a implementação da livre circulação de mercadorias na essência do propósito do MERCOSUL. Em: BOTELHO, Martinho Martins. Op. cit., p.178.

28 CAPARRO, Roberto. Op. cit., p.324.

29 Idem. 
e pequenas empresas.A pretensão em criar tais programas acarretou na formação de fundos destinados ao desenvolvimento da região, dentre os quais merece destaque o Fundo de Convergência estrutural do MERCOSUL - FOCEM, criado em 2006, com orçamento inicial de cem milhões de dólares americanos, no que Accioly chama de sopro de lucidez ${ }^{30}$, com objetivos de promover a competitividade das economias e regiões menos industrializadas, estimular a infraestrutura institucional. ${ }^{31}$

Em síntese, o FOCEM surgiu como uma maneira de implementar políticas compensatórias, especialmente com a funcionalidade de compensação financeira Sidepayments -, na tentativa de ajudar a estabilizar o bloco por meio do atendimento de interesses de parceiros menos satisfeitos com os resultados de sua inserção no bloco regional, o que poderia, por consequência, gerar grande instabilidade política e institucional. Em outras palavras, o FOCEM surgiu por insatisfação de Uruguai e Paraguai, os dois maiores beneficiados pelo fundo, que ameaçavam a desestruturação do bloco. ${ }^{32}$

Para ser beneficiado com o fundo, todo projeto é apresentado à Unidade Técnica Nacional FOCEM (UTN), que faz a avaliação das propostas e, em caso de elegibilidade, bem como em razão da relevância socioeconômica, os encaminha para o Conselho do Mercado Comum - CMC, e ainda, se validado, segue para as instâncias hierarquicamente superiores do bloco. ${ }^{33}$ Foi constituído por pelo menos dez anos e é composto dos recursos dos membros, da seguinte forma: Brasil (70\%); Argentina (27\%); Uruguai (2\%); Paraguai (1\%). A distribuição é inversamente proporcional, de forma que $48 \%$ do total sejam destinados a projetos paraguaios, contra $32 \%$ em favor do Uruguai e apenas $20 \%$ para Brasil e Argentina. ${ }^{34}$

No entanto, um grande obstáculo quanto aos objetivos do FOCEM em mitigar as assimetrias do bloco e desenvolver os seus quatro programas, - Programa de Convergência estrutural, Programa de Desenvolvimento da Competitividade, Programa de Coesão Social e

$30 \quad$ ACCIOLY, Elizabeth. Op. cit., p. 133.

CAPARRO, Roberto. Op. cit., p.326.

TESSARI, Gustavo Rosolen. Op. cit., p.133. Sobre o processo burocrático de avaliação de projetos, é importante salientar o caminho completo a ser
percorrido: "A UTN realiza, portanto, essa primeira avaliação e, uma vez cumpridas as exigências de ordem técnica, apresenta o projeto à Comissão de Representantes Permanentes do MERCOSUL (CRPM). Esta, por sua vez, verifica se os projetos apresentados atendem aos critérios de exigibilidade e, caso positivo, os repassa para a Unidade Técnica do FOCEM (UTF), que fica sob a responsabilidade do diretor da Secretaria do MERCOSUL (SM). A UTF realiza nova análise técnica dos projetos e os envia novamente à CRPM, que faz seu próprio relatório e o transmite ao Grupo de Mercado Comum (CMC), que por sua vez emite decisão final sobre os projetos (CMC nº18/2005, cap. IV)”'. Em: MELLO E SOUZA, André de; OLIVEIRA, Ivan Tiago Machado; GONÇALVES, Samo Sérgio. O fundo de convergência estrutural do MERCOSUL: agendas e propostas. Boletim de Economia e Política Internacional. Brasília, n.5, p. 7-16, jan./mar. 2011, p.9. 34

CAPARRO, Roberto. Op. cit., p.326. 
Programa de Fortalecimento da Estrutura Institucional e do Processo de Integração-, pode ser a intensa politização da escolha de projetos em razão do envolvimento do CPRM e do CMC. A estrutura ideal seria, pois, o envolvimento no processo de avaliação de projetos apenas de órgãos técnicos, a fim de evitar a influência negativa das decisões políticas. ${ }^{35}$

\section{A cooperação científica Internacional e no MERCOSUL}

A cooperação internacional no MERCOSUL foi concebida, desde os inícios do bloco, como uma ferramenta que permite fortalecer as capacidades de cada um dos Estados Partes e contribui para o aprofundamento do processo de integração regional.Para o desenvolvimento de programas e projetos de cooperação, os Estados Partes identificam e atualizam distintas áreas temáticas consideradas como prioritárias, tais como: saúde, educação, meio ambiente, gênero, comércio intrarregional, integração produtiva, cooperação científica entre outros.

O MERCOSUL, em face dos objetivos gerais traçados para a cooperação intra e extra bloco estabeleceu os seguintes princípios gerais: adequação com as prioridades de cooperação do bloco; solidariedade, em que o desenvolvimento deve sobrevir para todos os participantes; o respeito da soberania e a não ingerência nos assuntos internos dos países, pois nenhuma cooperação pode avançar sobre as forças soberanas dos Estados; a horizontalidade, em que os países intervenientes deverão estabelecer seus vínculos de cooperação como sócios no desenvolvimento; a não condicionalidade, com a obrigatoriedade de a cooperação estar livre de condicionamentos de políticas de qualquer índole; o consenso, com a cooperação devendo sempre ser negociada, planejada e executada e comum acordo entre os Estados cooperantes; a equidade, que obriga os acordos de cooperação o dever de distribuir seus benefícios de forma equitativa entre todos os participantes. O princípio também deve ser aplicado na distribuição de custos, que devem ser assumidos de forma proporcional às possibilidades reais de cada sócio. ${ }^{36}$

Além desses, também são princípios gerais: o benefício mútuo, em que cooperação internacional do MERCOSUL tem o dever de buscarem resultados favoráveis para os Estados ligados ao acordo; a natureza complementar da cooperação com os objetivos e políticas do Bloco Econômico; o respeito das particularidades culturais, históricas e institucionais dos

35 MELlO E SOUZA, André de; OLIVEIRA, Ivan Tiago Machado; GONÇALVES, Samo Sérgio. O fundo de convergência estrutural do MERCOSUL: agendas e propostas. Boletim de Economia e Política Internacional, Brasília, n.5, p. 7-16, jan./mar. 2011, p.14.

36 MERCOSUL. Objetivos e princípios. Disponível em: http://www.mercosur.int/innovaportal/v/6337/10/innova.front/objetivos-e-principios>. Acesso em: 29 jan. 2018. 
sócios na identificação bem como na formulação dos programas e projetos de cooperação; o protagonismo dos atores locais em todas as etapas dos programas e projetos de cooperação e a promoção de utilização do conhecimento, capital humano e instituições do MERCOSUL; a otimização da alocação de recursos para aumentar o alcance dos resultados dos projetos de cooperação, priorizando as associações com instituições e especialistas regionais que permitam uma maior sustentabilidade; o acesso à informação, baseado no princípio do Direito Administrativo da publicidade, em que a informação dos projetos, deve obrigatoriamente estar disponível para todos os participantes; Por fim, a gestão centrada no cumprimento dos resultados objetivamente verificáveis estabelecidos pelas partes para cada projeto. ${ }^{37}$

Observada a importância da cooperação internacional para a integração do Bloco, um dos caminhos para o cumprimento desses objetivos, como anteriormente enfatizado, é a área de cooperação científica, onde a universidade latino-americana possui amplo destaque como sendo protagonista nesse cenário. Assim, o propósito da internacionalização das universidades do MERCOSUL traduz-se na possibilidade de abrir frentes de cooperação internacional com o fortalecimento de temas-chaves para uma integração mais profunda, por meio de medidas concretas que possibilite o conhecimento mútuo, a mobilidade acadêmica, a cooperação em programas e projetos específicos e a formação de recursos humanos. ${ }^{38}$

Léa Velho já enfatizou em 2001 sobre a necessidade do nosso bloco econômico investir nas redes de cooperação em ciência e tecnologia. Infelizmente, pouco mudou de 2001 para cá no que se refere ao fraco desempenho empresarial na cooperação científica, o que faz com que o bloco não permita ainda que a cooperação fique dependendo do mercado, devendo criar oportunidades, identificar atores capacitados e criar incentivos financeiros e instrumentos para que se possa atingir os objetivos da criação do MERCOSUL. ${ }^{39}$

Não deve-se olvidar que a cooperação entre os Estados também faz parte da política aduaneira. A cooperação faz parte do processo de integração do bloco econômico e para a garantia dos direitos humanos. Enfatiza-se sua importância também pela postura adotada pelos organismos internacionais, reforçando a necessidade de integração regional para

\footnotetext{
37 Idem.

38 SENHORAS, Eloi Martins. O papel da internacionalização das universidades e a projeção da cooperação internacional do MERCOSUL. In: III Seminário Internacional Ciência e Tecnologia na América Latina, 2006, Campinas. Anais do III Seminário Internacional Ciência e Tecnologia na América Latina. Campinas: Unicamp, 2006.

39 VELHO, Léa. Redes regionais de cooperação em C\&T e o MERCOSUL. Parcerias estratégicas, Brasília, n.10, p.58-74, mar. 2001, p.70-71.
} 
reformular as políticas econômicas dos Estados para trazer a ideia de desenvolvimento com a criação de ações efetivas e com maior abrangência. ${ }^{40}$

Segundo Eloi Senhoras, os primeiros esforços para a formação de parcerias em ciência e tecnologia ocorreu em programas anteriores à criação do bloco, com os acordos bilaterais entre Brasil e Argentina na década de 1980. Posteriormente, com a consolidação do MERCOSUL, surgiu um fórum permanente institucionalizado para assuntos de C\&T, conhecido como Reunião Especializada em Ciência e Tecnologia - RECYT. As ações de integração universitária/científica desdobram-se em três planos distintos: a cooperação esporádica entre grupos e instituições; os acordos interinstitucionais bilaterais e os acordos interinstitucionais multilaterais ou redes. ${ }^{41}$

Uma das políticas do bloco econômico para fomentar a pesquisa e a formação de novos pesquisadores consiste no Prêmio MERCOSUL de ciência e tecnologia. Com premiação anual e criado em 1997 por decisão da Reunião Especializada em Ciência e Tecnologia do MERCOSUL - RECYT, o projeto objetiva reconhecer e premiar os trabalhos com mais relevância e pontuação oriundos de pesquisas de estudantes, jovens pesquisadores, grupos de pesquisa e pesquisadores seniores, que representem uma potencial contribuição ao desenvolvimento científico e tecnológico dos países membros e associados do MERCOSUL. Além disso, a premiação busca incentivar a realização de pesquisa científica, tecnológica e de inovação no bloco econômico e também busca contribuir para o processo de integração regional mediante o aumento da difusão de conquistas e avanços no campo do desenvolvimento científico e tecnológico na região $0^{42} / 43$, criando um cenário, a médio prazo, facilitador, para o processo de integração.

40 WINTER, Luís Alexandre Carta. Op. cit., p.125.

41 SENHORAS, Eloi Martins. O papel da internacionalização das universidades e a projeção da cooperação internacional do MERCOSUL. In: III Seminário Internacional Ciência e Tecnologia na América Latina, 2006, Campinas. Anais do III Seminário Internacional Ciência e Tecnologia na América Latina. Campinas: Unicamp, 2006.

42 MERCOSUl. Prêmio MERCOSUL de Ciência e Tecnologia 2017. Disponível em: < http://www.mercosur.int/innovaportal/v/8512/2/innova.front/pr\%C3\%AAmio-mercosul-de-ci\%C3\%AAncia-etecnologia-2017>. Acesso em: 03 fev. 2018.

43 Segundo o sítio oficial da premiação, "o prêmio é organizado pelo Ministério da Ciência, Tecnologia, Inovação e Comunicações do Brasil (MCTIC) e pelo Conselho Nacional de Desenvolvimento Científico e Tecnológico (CNPq), além de contar com o apoio institucional do Movimento Brasil Competitivo (MBC) e dos organismos de ciência e tecnologia dos países membros (Ministério de Ciência, Tecnologia e Inovação Produtiva da Argentina; Conselho Nacional de Ciência e Tecnologia do Paraguai; e Ministério de Educação e Cultura do Uruguai) e de países associados do MERCOSUL.” Em: MERCOSUL. Prêmio MERCOSUL de Ciência e 
A política aduaneira, além de uma medida protetiva para o mercado da América do Sul, é uma ação integracionista, ao acarretar que a união de forças econômicas, políticas e científicas possam reservar resultados benéficos para toda a comunidade. Ao buscar acordos internacionais para o bloco econômico ou mesmo permitir a livre-circulação de bens, serviços e pessoas, o mercado regional na área científica sofre com a possibilidade de um multiculturalismo nunca antes imaginado. Programas de intercâmbio, brasileiros em universidades estrangeiras e vice-versa foram facilitados com a assinatura de acordos e diminuição dos trâmites burocráticos de viagem e residência para os Estados-membros. Igualmente, a comercialização de produtos locais sensíveis aos projetos de pesquisadores do bloco tornou-se facilitado e mais barato, com a livre-circulação de bens.

Se se considera a importância da política aduaneira para a cooperação científica, devese ainda lembrar que os Estados pertencentes ao bloco possuem a "tarefa de viabilizar o rompimento do processo de dependência tecnológica no qual estão embrenhadas as sociedades subdesenvolvidas" 44 , inclusive por um mandamento constitucional existente em cada carta fundamental dos Estados-membros.

Nesse sentido, é impreterível trazer os recortes das Constituições dos referidos Estados-membros. O Brasil, de acordo com os artigos $3^{\circ}$, II e 218, tem o dever, para garantir o desenvolvimento nacional, promover e incentivar o desenvolvimento científico, a pesquisa e a capacitação tecnológica por meio da realização de políticas públicas; Na Argentina, o Congresso possui como atribuição "proveer lo conducente [...] a la investifación y al desarollo científico y tecnológico, su dufisión y aprovechamiento" ${ }^{45}$; No Estado Paraguaio, "el Estado fomentará [...] la investifación científica y tecnológica" constitución de fondos para becas y otras ayudas, con el objeto de facilitar la formación intelectual, científica, técnica o artística" ${ }^{47}$, bem como "[...] un regimén de estímulo para introducción e incorporación al país de los elementos necessários para el ejercicio de las artes y investigación científica y tecnológica, así como para su difusión en el país y en el extranjero" ${ }^{48}$; No Uruguai, "el Estado propenderá al desarollo de la investigación científica $y$ de la enseñanza técnica" ${ }^{49}$, bem como "la creación de becas de perfeccionamiento y

44 GRAU, Eros Roberto. A ordem econômica na Constituição de 1988. São Paulo: Malheiros, 2017, p.261.

45 Artigo 75 da Constituição da Nação Argentina.

$46 \quad$ Artigo 76 da Constituição da República do Paraguai.

$47 \quad$ Artigo 79 da Constituição da República do Paraguai.

$48 \quad$ Artigo 83 da Constituição da República do Paraguai.

$49 \quad$ Artigo 70 da Constituição da República Oriental do Uruguai.

Revista Juris Poiesis - Rio de Janeiro. Vol.21-n²6, 2018, pg.135 - 152 . ISSN 2448-0517

Rio de Janeiro, 30 de agosto de 2018. 
especialización cultural, científica y obrera" ${ }^{, 50}$; $\mathrm{Na}$ Venezuela, quinto Estado-membro, defende em sua Constituição a liberdade ao "derecho a la inversión, producción y divulgación de la obra creativa, científica, tecnológica y humanística" ${ }^{51}$ Como se observou, as Constituições dos membros do bloco têm integralizada a importância da cooperação científica para com o desenvolvimento humano.

\section{Conclusão}

O presente artigo pretendeu demonstrar, com maior profundidade, o dinamismo existente nas pretensões no Mercado Comum do Sul e de sua política aduaneira, indo muito além da concepção superficial que se tem sobre sua importância. Os mecanismos atualmente utilizados pelo bloco econômico, em especial a cooperação internacional, têm como escopo não somente proibir ou permitir a circulação de algum produto, mas sim possibilitar um sistema de troca de patentes e compartilhamento de pesquisas científicas que forçosamente são transformados em benefícios para a sociedade comunitária.

As consequências de criação de uma comunidade científica regional integralizada pode ser observada, na União Européia, dentre seus muitos exemplos, a fabricação conjunta de um caça militar europeu, o Eurofighter, que contou com a participação do Reino Unido, Alemanha, Itália e Espanha ${ }^{52}$, ou o programa Erasmus Mundus, programa de mobilidade acadêmica financiado pela União Européia que objetiva "promover a excelência da educação superior e pesquisa dos países europeus e ao mesmo tempo reforçar os laços acadêmicos com os países de todo o mundo". ${ }^{53} \mathrm{O}$ que se percebe também é que a noção comunitária supera as barreiras territoriais dos próprios Estados-membros dos blocos, beneficiando a todo o globo, com projetos e instrumentos que podem ser utilizados por um indivíduo não pertencente à comunidade de países.

Assim, a defesa por uma maior integração do MERCOSUL, fortalecendo sua política aduaneira através da padronização legiferante, tarifa única e criação de projetos de cooperação é um assunto sério e que deve ser tratado com maior importância pelos líderes locais. Afinal, não se construiu uma Europa unida do dia para a noite e, outrossim, não se construirá uma

\footnotetext{
$50 \quad$ Artigo 71 da Constituição da República Oriental do Uruguai.

$51 \quad$ Artigo 98 da Constituição da República Bolivariana da Venezuela.

52 Eurofighter Typhoon. About us. Disponível em: 〈https://www.eurofighter.com/about-us〉. Acesso em: 04 fev. 2018
}

53 Erasmus Mundus. O que é o programa Erasmus Mundos? Disponível em: <http://erasmusmundusnobrasil.webs.com/programa.htm>. Acesso em: 04 fev. 2018. 
América latina em um dia. No entanto, os esforços para fortalecer a coalizão regional devem ser dobrados e não, tampouco, continuar com visões limitadas e antiquadas de soberania local.

\section{Referências}

Associação Latino Americana de Integração. Disponível em: <http://www.aladi.org/sitioAladi/quienesSomos.html>. Acesso em: 03 fev. 2018.

ACCIOLY, Elizabeth. Duas décadas de MERCOSUL: valeu a pena? Revista Lusíada, Lisboa, n.5, p.125-140, 2011.

ARGENTINA. Constituição da República Argentina. Buenos Aires: 1853.

CAPARRO, Roberto. Comércio Internacional Esquematizado. São Paulo, Saraiva, 2012.

BOTELHO, Martinho Martins. Novo Mecanismo de Distribuição de Renda TributáriaAduaneira no MERCOSUL. Revista Eletrônica do Curso de Direito das Faculdades OPET. Curitiba, n. 9, p. 171-182, jan./jun. 2013.

GRAU, Eros Roberto. A ordem econômica na Constituição de 1988. São Paulo: Malheiros, 2017.

KUME, Honorio; PIANI, Guida. Mercosul: o dilema entre união aduaneira e área de livrecomércio. Revista Economia Política, São Paulo, v.25, n.4, p.370-390, 2005.

MELlO E SOUZA, André de; OLIVEIRA, Ivan Tiago Machado; GONÇALVES, Samo Sérgio. O fundo de convergência estrutural do MERCOSUL: agendas e propostas. Boletim de Economia e Política Internacional. Brasília, n.5, p. 7-16, jan./mar. 2011.

MERCOSUL. Objetivos e princípios. Disponível em: < http://www.mercosur.int/innovaportal/v/6337/10/innova.front/objetivos-e-principios>. Acesso em: 29 jan. 2018.

MERCOSUl. Prêmio MERCOSUL de Ciência e Tecnologia 2017. Disponível em: < http://www.mercosur.int/innovaportal/v/8512/2/innova.front/pr\%C3\%AAmio-mercosul-deci\%C3\% AAncia-e-tecnologia-2017>. Acesso em: 03 fev. 2018.

PARAGUAI. Constituição da República do Paraguai. Assunção: 1992.

SENHORAS, Eloi Martins. O papel da internacionalização das universidades e a projeção da cooperação internacional do MERCOSUL. In: III Seminário Internacional Ciência e Tecnologia na América Latina, 2006, Campinas. Anais do III Seminário Internacional Ciência e Tecnologia na América Latina. Campinas: Unicamp, 2006.

SCHOUERI, Luís Eduardo. Harmonização Tributária no MERCOSUL. Revista Direito Mackenzie, São Paulo, n.2, p.169-178, 2015.

STUDART, Rogério; HERMANN, Jennifer. Estrutura e operação dos sistemas financeiros do MERCOSUL: perspectivas a partir das reformas institucionais dos anos 1990. Brasília: IPEA, 2001. 
TESSARI, Gustavo Rosolen. Integração regional, fundos estruturais e estabilidade institucional no MERCOSUL: a criação do FOCEM. Perspectivas, São Paulo, v.42, p.115137, jul./dez. 2012, p.122.

URUGUAI. Constituição da República Oriental do Uruguai. Montevidéu: 1997.

VARELLA, Marcelo D. Direito Internacional Público. São Paulo: Saraiva, 2016.

VELHO, Léa. Redes regionais de cooperação em C\&T e o MERCOSUL. Parcerias estratégicas, Brasília, n.10, p.58-74, mar. 2001.

VENEZUELA. Constituição da República Bolivariana da Venezuela. Caracas: 1999.

WINTER, Luís Alexandre Carta. Desenvolvimento e integração regional: a atuação do MERCOSUL em políticas públicas de direitos humanos. Revista de direitos humanos em perspectiva, Curitiba, v.2, n.2, p.112-127, jul./dez. 2016.

Submetido em: 04/07/18

Aceito em: 23/07/2018 